\title{
EDITOR'S
}

doi: 10.1590/S1677-5538.IBJU.2014.06.01

\section{Sexual stereotypes in Medicine}

Sexuality is a doubtless complex topic. Several personal experiences, social issues, cultural characteristics, psychosocial interpretations, medical literature, philosophical demands and ethical aspects, among others, are related to it and all are equally important. Due to its multidimensional characteristic, sexuality is omnipresent in life of all human beings in spite of the time consumed to formalize its specific study. Many disciplines and varied focus have considered sexuality under different points of view, due to its rich characteristics, exposing its complexity.

In spite of the diversity of approaches, there are nowadays many consensus that are considered necessary, and many are associated to two main questions: a. science evolution, that provides more reliable and precise answers and not opinions, and b. definition, declaration, sexual rights defense and promotion in order to achieve sexual health. But sometimes the dialogue between these two central aspects may not translate into a specific practical expression. I want to refer to this topic, through a particular question.

Last October, São Paulo housed the International Congress of Sexual Medicine. In some presentations - based on the biomedical paradigm (1) as well as those related to bio-psycho-social aspects (2) presented some data using images that were a form of visual stimulation of the researched information. I want to comment the use of sexual stereotyped images of "heterosexual young whites with a modeled beauty pattern". We must remember that "simple stereotypes may be oppressive and when they are prescriptive, they may be immoral and illegal, or, what should people do or not be allowed to? (3).

This use of stereotyped images reminds me of two important medical questions related to:

a) Ethics: some argue that medical ethics presents two very specific sides, with antagonistic aspects, even if not opposites. The first side, ethics, that we call "E", deals with important practical questions that achieve rapidly a consensus, even only for being political correct. Health bioethics relates to controversial strong topics, far away from day-by-day practice. The second is related to daily activities, and almost always deals with practical aspects of consultation, conversation and sharing: "everyone has his own conscience". 


\section{EDITOR'S}

b) Scientific aspects: in order to explain these aspects, we must wonder if sexuality in centered in genitals or if it is related to multiple and multidimensional aspects of the human being.

It is not a simple moral stance. I think the ethical question has epistemological characteristics that we include when we use certain images in a particular context. I would like to ask readers if when we select sexual images for our presentations do we really follow any process of selection according to our idea of sexuality? We ourselves have the answer to that question, as with all ethical questions. And we must figure out that this is a way of our expression.

In relation to the second, the situation is far more complex, since in this particular we cannot deny evidences. The question is more specific, controversial and disturbing: which value do we assign to sexual stereotypes as causes of sexual health disturbances? In order to analyze this aspect, we must recall the theory of sexual scripts by Gagnon \& Simon, that stated that "they provide an useful landmark for the understanding of the sexual roles of men, women, boys and girls during intercourse" (4). Secondly, we must stress the importance of health promotion - in our case sexual health - for the medical practice, regardless the personal effort. Modern medicine usually investigates troublesome situations regarding sexual function, seeking answers to specific sexual disorders to determine better diagnosis and to propose better treatments, in order to promote health allowing people a better routine life. "Multiple approaches for promotion of sexual health are necessary due to biological, psychological and sociological aspects of people's life" (5). Now I return to my almost rhetorical question: can we at present sustain sexual stereotypes being ourselves health care professionals?

I want to point out that the proposed sexual rights that we profess must not be lightly used but be applied according to our attitudes, skills and messages. I believe that health care is systematically and routinely pursuing this goal, particularly sexual science in this new millennium.

As health care providers, it is useful to remind us that we not always have the necessary resources to attend all possible demands. There must be a Hippocratic principle to guide and stimulate us: "some patients, although aware of the sensitive condition, regain health through the kind interaction with their doctors". An effective example of this is to avoid stereotypes to be used and reinforced, avoiding damage to the people. 


\section{EDITOR'S}

\section{REFERENCES}

1. Menéndez EL: El modelo médico hegemónico: transacciones y alternativas hcia una fundamentación teórica del modelo de autoatención en salud. Arxiu d'etnografia de Catalunya. 1984; 3: 85-119.

2. Engel GL. The need for a new medical model: a challenge for biomedicine. Science. 1977;196:129-36.

3. Cook RJ, Cusack S, Dickens BM. Unethical female stereotyping in reproductive health. Int J Gynaecol 0bstet. 2010;109:255-8.

4. Sanchez DT, Fetterolf JC, Rudman LA. Eroticizing inequality in the United States: the consequences and determinants of traditional gender role adherence in intimate relationships. J Sex Res. 2012;49:168-83.

5. Aggleton P, de Wit J, Myers T, Du Mont J. New outcomes for sexual health promotion. Health Educ Res. 2014;29:547-53.

Francisco Juan José Viola, MD, PhD

Licensed physician in science of family and sexuality Master degree in sexual therapy $\mathrm{PhD}$ in psychology familiar guidance and sexuality E-mail: francisco.viola@hotmail.com 